\title{
Cardiac Tamponade in Systemic Lupus Erythematosus. Report of Four Cases
}

\author{
Márcia Bueno Castier, Elisa M. N eves A lbuquerque, Maria Eduarda F. Costa Castro Menezes, \\ Evandro Klumb, Francisco Manes Albanesi Fo
}

Rio de Janeiro, RJ - Brazil

\begin{abstract}
Objective - To report and assess the incidence of cardiac tamponade in systemic lupus erythematosus as a cardiac manifestation of the disease.

Methods - We reviewed the medical records of 325 patients diagnosed with systemic lupus erythematosus according to the American Rheumatism Association and their complementary laboratory tests compatible with cardiac tamponade.
\end{abstract}

Results - In the 325 medical recors reviewed, we found 108 patients with pericardial effusions corresponding to $33.2 \%$ of the total and $54 \%$ of the patients studied in the active phase of the disease. Clinical assessment and transthoracic echocardiogram allowed the clinical diagnosis of cardiac tamponade in only 4 (1.23\%) patients, 3 of whom were females, white, with ages ranging from 25 to 44 years. The pericardial fluid was hemorrhagic or serosanguineous with high levels of FAN and positivity for LE cells. In the treatment, we successfully used pericardicentesis associated with high doses of corticosteroids. In clinical and laboratory follow-up performed for a period of 3 years, neither recrudescence of the pericardial effusion nor evolution to constriction occurred.

Conclusion - Even though rare (1.23\%), cardiac tamponade in patients with systemic lupus erythematosus has a benign evolution when properly treated, according to our experience.

Key words: cardiac tamponade, systemic lupus erythematosus, pericardial effusion

Report of Four Cases Rio de Janeiro, RJ - Brazil

Hospital Universitário Pedro Ernesto - UERJ

Mailing address: Márcia Bueno Castier - Av. Epitácio Pessoa 4254/201 - 22471001 - Rio de Janeiro, RJ, Brazil

English Version by Stela Maris C. Gandour
Systemic lupus erythematous is a collagen disease that often involves the heart, the pericardium being the most commonly affected site, resulting in clinical ${ }^{1-9}$ and anatomopathological ${ }^{10-14}$ manifestations. This involvement is usually pericardial effusion, most of the time of mild intensity ${ }^{6,7,15-17}$. In a few patients, pericardial involvement may be the initial form of presentation of systemic lupus erythematosus ${ }^{5-7}$. Cardiac tamponade is a rare clinical manifestation ${ }^{15}$, and very few cases are reported as the first manifestation of the disease ${ }^{18-20}$.

Our study aims to assess the frequency of cardiac tamponade in patients with systemic lupus erythematosus being followed up in a specialized sector of a tertiary hospital.

\section{Methods}

We reviewed 325 medical records of patients with systemic lupus erythematosus, who were being followed up in the Sector of Collagen Diseases of the Rheumatology Service of HUPE-UERJ, during the period from March '91 to October ' 98 . The diagnosis of systemic lupus erythematosus met the criteria adopted by the American Rheumatism Association (ARA) ${ }^{21}$. To characterize disease activity, we used the criteria of SLEDAI (Systemic Lupus Erythematosus Disease Activity Index) ${ }^{22}$. All patients studied had at least one transthoracic echocardiography that was performed independently from the presence of cardiovascular signals or symptoms, or both, because of the development of several study protocols.

The echocardiographies were performed with Toshiba SSH-65 ${ }^{\mathrm{A}}$ and Apogee CX 200 devices, which provided single-dimensional and two-dimensional recordings and flow study with Doppler and color mapping. The echocardiographic measurements were obtained according to the guidelines of the American Society of Echocardiography ${ }^{23}$. Once the presence of pericardial effusion was detected, it was classified as mild, moderate, or severe ${ }^{24}$. We assessed the presence of signals that could indicate increase in intrapericardial pressure, such as respiratory variations of the 
right ventricular dimensions ${ }^{25,26}$, collapse of the right atrial wall during diastole ${ }^{27}$, and diastolic invagination of the right ventricular anterior wall ${ }^{28}$. On Doppler echocardiography, we assessed a drop in mitral and aortic flows during inspiration $^{29}$.

For the diagnosis of cardiac tamponade, we used data from clinical examinations, such as paradoxical pulse associated or not with reduction in intensity of the cardiac sounds, pathological jugular venous distension, and arterial hypotension. These data supported by echocardiographic findings of pericardial effusion associated with signals of increase in the intrapericardial pressure established the definitive diagnosis of cardiac tamponade.

\section{Results}

We reviewed 325 medical records and found 108 patients with pericardial effusion, corresponding to $33.2 \%$ of the total number of patients and to $54 \%$ of the patients studied in the active phase of the disease. Only 4 (1.23\%) patients met the criteria for the diagnosis of cardiac tamponade. Three of these 4 patients were females, white, with ages ranging from 25 to 44 years ( mean $=32.25$ years), had a previous diagnosis of systemic lupus erythematosus, and underwent pericardicentesis.

We were able to perform echocardiography during and immediately after the procedure in 3 patients (fig. 1). The analysis of the pericardial fluid revealed a hemorrhagic aspect in 2 patients and a serosanguineous aspect in the other 2. In all patients LE cells were present, the search for ANF was positive (levels ranging from 1/32 to 1/128), and cultures for microorganisms were negative. Later, other causes of pericardial effusion, such as hypothyroidism, uremia, and tuberculosis were discarded through laboratory tests. Disease activity was confirmed in all patients.

In addition to pericardicentesis, the treatment included high doses of corticosteroids (2-3 mg/kg of prednisone or equivalent) with control of disease activity. The patients were followed up with serial echocardiographic studies during a period from 9 to 60 months (mean $=27$ months). We detected neither recrudesce of pericardial effusion nor evolution to the constrictive form.

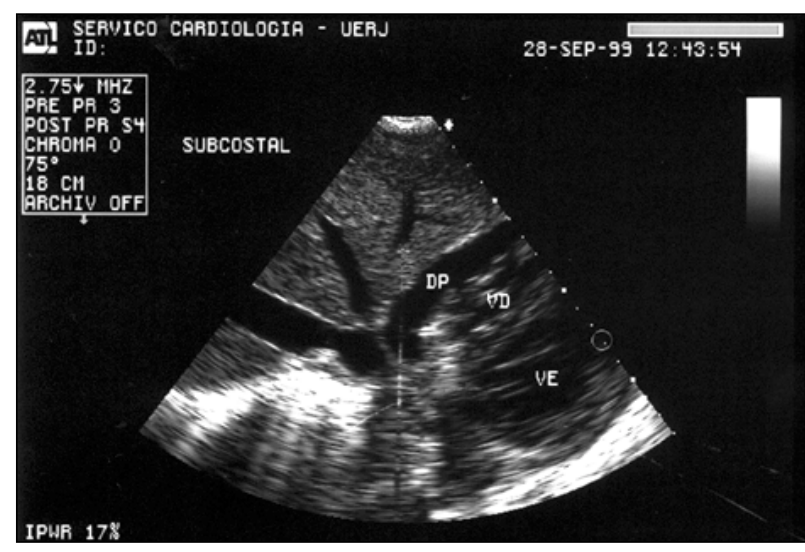

Fig. 1 - Echocardiogram performed immediately after pericardicentesis with immediate relief of symptoms showing residual pericardial effusion

\section{Discussion}

Even though pericarditis in systemic lupus erythematosus has already been well described in regard to its clinical ${ }^{1-9}$, anatomicopathological ${ }^{10-14}$ and echocardiographic characteristics ${ }^{30-36}$, occurrence of cardiac tamponade is rare, with 12 cases reported until $1986^{37}$. To establish the differential diagnosis with other etiologies, it is important to know the characteristics of the fluid, which may have a hemorrhagic aspect, low levels of complement, high levels of ANF, and the presence of LE cells ${ }^{38,39}$.

Several isolated cases have been reported ${ }^{40-44}$, and in some of these cardiac tamponade was the initial manifestation of the rheumatic disease. All our patients had a previous diagnosis of systemic lupus erythematosus, which certainly made the clinical diagnosis easier. An isolated case of cardiac tamponade with associated polyarteritis has been reported, in which the patient died because of the clinical severity of both diseases ${ }^{45}$. In our experience, even though the initial findings indicated great instability, we had a very good response to high doses of corticosteroids initiated after pericardial effusion withdrawal. These patients were followed up during a period from 9 to 60 months, and neither new pericardial effusion nor evolution to constriction was detected with echocardiography.

\section{References}

1. Libman E, Sacks B. A hithertho undescribed form of valvular and mural endocarditis. Arch Intern Med 1924; 2433: 701-37.

2. Dubois EL, Tuffanelli DL. Clinical manifestations of systemic lupus erythematosus. Computer analysis of 520 cases. JAMA 1964; 190: 104-11.

3. Jessar RA, Lamont-Havers RW, Ragan C. Natural history of lupus erythe matosus disseminatus. Ann Intern Med 1953, 38: 717-31.

4. Harvey AM, Shulman LA, Tumulty PA. Systemic lupus erythematosus. Review of the literature and clinical analysis in 138 cases. Medicine 1959; 58: 291-437.

5. Shearn MA. The heart in systemic lupus erythematosus. Am Heart J 1959; 58: 452-66.
6. Mandell BF. Cardiovascular involvement in systemic lupus erythematosus Semin Arthritis Rheum 1987; 17: 126-41.

7. Ansari A, Larson PH, Bates HD. Cardiovascular manifestations of systemic lupus erythematosus; current perspective. Prog Cardiovasc Dis 1985; 27; 421-34.

8. Carette S. Cardiopulmonary manifestations in systemic lupus erythematosus. Rheum Dis Clin North Am 1988; 14; 135-47.

9. Bridgen $\mathrm{W}$, Baywater GL, Lessof MH. The heart in systemic lupus erythe matosus. Br Heart J 1960; 22: 1-16.

10. Gross L. The cardiac lesions in Libman-Sacks disease with consideration of its relationship to acute diffuse lupus erythematosus. Am J Pathol 1940; 16: 375 407. 
11. Griffith GC, Vural IL. Acute and subacute disseminated lupus erythematosus. A correlation of clinical and postmortem findings in eighteen cases. Circulation 1951; 3: 492-500.

12. Humpheys EM. The cardiac lesion of acute disseminated lupus. Ann Intern Med $1948 ; 28: 12-4$.

13. Kong TQ, Kellum RE, Haserick JR. Clinical diagnosis of cardiac involve ment in systemic lupus erythematosus. A correlation of clinical and authopsy findings in thirty patients. Circulation 1962; 26: 7-11.

14. Copeland GD, Van Capeller D, Stern TN. Systemic lupus erythema tosus: Clinical report of forty seven cases with pathological findings in eighteen. Am J Med Sci 1958; 236: 318-26.

15. Hetjmancik MR, Wright JC, Quint R, Jenning FL. The cardiovascular manifestations of systemic lupus erythematosus. Am Heart J 1964; 68: 119-30.

16. Estes D, Chistian CL. The natural history of systemic lupus erythematosus. Medicine 1971; 50: 85-95.

17. Doherty NE, Siegel RJ. Cardiovascular manisfestations of systemic lupus erythematosus. Am Heart J 1985; 110: 1257-65.

18. Reiner JS, Furie RA. Cardiac tamponade as an initial manifestation of systemic lupus erythematosus. J Rheumatol 1989; 16: 1127-9.

19. LeeIH, Yang SC, Kim TH, etal.Cardiactamponadeas aninitialmanifestation of systemic lupus erythematosus — single case report. J Korean Med Sci 1997; 12: 75-7.

20. Nour-Eddine M, Bennis A, Soulami S, Chraibi N. Cardiac tamponade disclosing systemic lupus erythematosus. Ann Cardiol Angeiol 1996; 45: 71-3.

21. Tan EM, Cohen AS, Fries JF, et al. The 1982 revised criteria for the classification of systemic lupus erythematosus. Arthritis Rheum 1982; 25: 1271-7.

22. Bombardier C, Gladman DD, Urowitz MB, Caoron D, Chang C. Derivation of the SLEDAI. A disease activity index for lupus patients. Arthritis Rheum 1992; 35 630-40.

23. Sahn DJ, De Maria A, Kisslo J, Weyman AE. Recommendations regarding quantitation in M-mode echocardiography: Results of a survey of echocardiographic measurements. Circulation 1978; 58: 1072-83.

24. Horowitz MS, Schultz CS, Stirson EB, Harrison DC, Popp RL. Sensitivity an specificity of echocardiographic diagnosis of pericardial effusion. Circulation 1974; 50: 239-47.

25. D'Cruz IA, Cohen HC, Prabhu R. Diagnosis of cardiac tamponade by echocardiography. Changes in mitral valve motion and ventricular dimensions with special reference to paradoxical pulse. Circulation 1975; 52: 460-5.

26. Schiller NB, Botvinick EH. Right ventricular compression as a sign of cardiac tamponade. An analysis of echocardiographic ventricular dimensions and theur clinical implication. Circulation 1977; 56: 774-9.

27. Gillam LD, Guyer D, Gibson TC, King ME, Marshall JE, Weyman AE. Hydrodynamic compression of the right atrial free wall, a knew highly sensitive echocardiographic sign of cardiac tamponade. Circulation 1983; 68: 294-301.

28. Armstrong WF, Schildt B, Helper DJ. Diastolic collapse of the right ventricle with cardiac tamponade: an echocardiographic study. Circulation 1982; 65: 1491-6.

29. Appleton CP, Hatle LK, Popp RL. Cardiac tamponade and pericardial effusion: respiratory variation in transvalvular flow velocities studied by Doppler echocardiography. J Am Coll Cardiol 1988; 11: 575-9.

30. Li EK, Crozier IG, Milne MJ, Nocholls MG. Cardiac involvement in systemic lupus erythematosus. Arthritis Rheum 1989; 32: 116-6.

31. Chia BL, Mah EP, Feng PH. Cardiovascular abnormalities in systemic lupus erythematosus. J Clin Ultrasound 1981; 9: 237-43.

32. Maniscalco BS, Flener JM, McCans JL, Chiapella JA. Echocardiographic abnormalities in systemic lupus erythematosus. Circulation 1975; 52(supl.2): 211

33. Ito M, Kugyama Y, Omura I. Cardiovascular manifestations of systemic lupus erythematosus. Jpn Circ J 1979; 43: 985-94.

34. Crozier IG, Li EK Milne MJ, Nicholls MG. Cardiac involvement in systemic lupus erythematosus detected by echocardiography. Am J Cardiol 1990; 65: 1145-8.

35. Doherty NE, Feldman G, Mauner G, Siegel RJ. Echocardiographic findings in systemic lupus erythematosus. Am J Cardiol 1988; 61: 1144.

36. Klinkoff AV, Thompson CR, Reid RD, Tomlinson CW. M-Mode and twodimensional echocardiographic abnormalites in systemic lupus erythematosus, JAMA $1985 ; 252$ : 3273-7

37. Rudra T, Evans PA, O'Brien EN. Systemic lupus erythematosus presenting with cardiac tamponade cardiac tamponade due to haemorragic effusion. Postgrad Med J 1987; 63: 567-8.

38. Hunder GC, Mullen BJ, McDuffie FC. Complement in pericardial fluid of lupus erythematosus. Ann Intern Med 1974; 80: 453-8.

39. Averbuch M, Bojko A, Levo Y. Cardiac tamponade in the early post partum period as the presenting and predominant manifestation of systemic lupus erythematosus. J Rheumatol 1986; 13: 444-5.

40. Zashin SJ, Lipsky PE. Pericardial tamponade complicating systemic lupus erythematosus. J Rheumatol 1989; 16: 374-7.

41. Carrol N, Barret JA. Systemic lupus erythematosus presenting with cardiac tamponade. Br Heart J 1984; 51: 542-3.

42. Ehrenfeld M, Asman A, Spilberg O, Samra Y. Cardiac tamponade as the presenting manifestation of systemic lupus erythematosus. Am J Med 1989; 86: 626-7.

43. Porcel JM, Selva A, Tornos MP, Galve E, Soler-Soler J. Resolution of cardiac tamponade in systemic lupus erythematosus with indometacine. Chest 1989; 96: 1193-4

44. Manresa JM, Gutierrez L, Viedma P, Alfani O. Cardiac tamponade as a clinical symptom of systemic lupus erythematosus. Rev Esp Cardiol 1997; 50: 600-2.

45. Costa AC, Mansur AJ, Assi VC, Grinberg M, Bellotti G, Pileggi F. Tamponamento cardíaco fatal em paciente portadora de lúpus eritematoso sistêmico associado a vasculite semelhante a poliarterite nodosa. Arq Bras Cardiol 1990; 55: 197-9. 